Radiocarbon, Vol 58, Nr 1, 2016, p 231-232

DOI:10.1017/RDC.2016.11

(C) 2016 by the Arizona Board of Regents on behalf of the University of Arizona

\title{
RESPONSE TO “COMMENT ON 'INVALIDATION OF THE INTRACAVITY OPTOGALVANIC METHOD FOR RADIOCARBON DETECTION' " BY DANIEL E MURNICK
}

\author{
Cantwell G Carson* \\ National Energy Technology Laboratory, Pittsburgh, Pennsylvania, USA.
}

ABSTRACT. Our results, when taken alongside those of two other research groups, appear to invalidate the early positive results for intracavity optogalvanic spectroscopy (ICOGS) and its detection of radiocarbon. Daniel Murnick, whose lab published those early results, has directed a comment setting out the perceived shortcomings of our article and the reasons that the results do not constitute invalidation, as our article claims. Absent support from his own findings or published literature, his various counterclaims regarding our experimental procedure appear to constitute only his considered professional opinion and the largest confounder highlighted by our research is not even mentioned. The preponderance of documented evidence regarding ICOGS clearly supports the null hypothesis and in our opinion, nothing in Murnick's comment indicates otherwise.

\section{RESPONSE}

Daniel Murnick has submitted a comment in defense of his earlier publications regarding the detection of radiocarbon with intracavity optogalvanic spectroscopy (ICOGS), in which he points out perceived shortcomings in our research (Carson et al. 2016). Whereas we would expect insightful criticism from such an eminent scholar in the field, we were instead dismayed to read weak and unsubstantiated counterclaims to our findings.

His first criticism is that we should have demonstrated unequivocally that his earlier results could not be reproduced under identical conditions. We felt that this had already been accomplished in two different laboratories, at Groningen University and at Uppsala University (Persson et al. 2013; Paul and Meijer 2015; Persson and Salehpour 2015), but he arbitrarily disregards their findings. For what reason should we also disregard the invalidating results from other laboratories when no evidence is produced to discredit them?

Second, he claims that the theoretical basis for our findings was invalid. Our theoretical basis is an extension of the model he espoused in his own peer-reviewed publications. Compare what we present against his own model (Murnick et al. 2008). We expanded one of his products into an integral and placed rough bounds on his own otherwise unspecified term $K$, which "is a corresponding optogalvanic proportionality constant that depends on the details of the electric discharge" (Murnick et al. 2008). If our model is invalid because of the reasonable caveats of Bachor et al. (1982), should this not also challenge his own published model?

Third, he claims that the crucial flaw in our experiment was that we used sawtooth modulation, "[making] the intrinsically narrow band $\mathrm{CO}_{2}$ laser effectively broadband." Rather than provide evidence drawn from a comparable $\mathrm{CO}_{2}$ laser operated in a similar fashion, the support is claimed from an entirely different system (Genoud et al. 2015). The "lower sensitivity" found by Genoud et al. compared to Galli et al. (2013) was attributed by Munick to the line scanning, not to any of the other potential sources of discrepancy. Genoud et al. was working at $\sim 275 \mathrm{~K}$ at 20 mbar with a $3-\mathrm{mW}$ quantum cascade laser, whereas Galli (2013) was operating at $195 \mathrm{~K}$ at $11.6 \mathrm{mbar}$ with a $30-\mathrm{mW}$ Ti:sapphire laser. Is it fair to disqualify our experimental system because two other systems, based on completely different principles with completely different equipment, had a differing results?

*Corresponding author. Email: carsonc@netl.doe.gov 
Fourth, he makes the unsubstantiated counterclaim, "In order to measure ${ }^{14} \mathrm{CO}_{2}$ content with wavelength modulation it is best to use square wave modulation with a voltage equal to about ..." This statement is nothing but speculation. There is no precedent or experiment upon which to base this claim, thereby making it impossible to evaluate. Likewise with his insistence on the use of an optogalvanic reference cell instead of a photodiode: perhaps it would be better, but no evidence is presented to support this. If, for the sake of argument, we accepted the foregoing unsubstantiated counterclaims, which of the claims of our own report would still stand? We claimed that the optogalvanic measurements at the various ${ }^{14} \mathrm{CO}_{2}$ lines were primarily the result of nearby ${ }^{12} \mathrm{CO}_{2}$ lines resonances such as $\mathrm{P}(19)$ e and $\mathrm{Q}(13)$ e. We claimed that these lines constituted an unrecognized confounder in the previously published research on this topic. We claimed that this confounder was so large that it would have rendered detection of ${ }^{14} \mathrm{CO}_{2}$ at the part-per-trillion level with the precision claimed was impossible. Given that none of these claims were challenged, we must assume that Murnick has conceded them. This again challenges his own claims (Murnick et al. 2008), which make no mention of these confounding factors.

Three research groups outside of Murnick's laboratory have now attempted to reproduce his results and all three attempts have been foundered in their considerable efforts. With the exception of a few of Murnick's own conference presentations, nothing has been presented beyond what was in Ilkmen's thesis (2009) that supports the initial promise of ICOGS. Murnick's citation to his recent conference presentation (Murnick 2015) is unpublished; it is simply a review of the subject and appears to offer nothing new. Instead, a raft of peer-reviewed research has been produced documenting failure by other groups to recreate any sign of the resolving power promised in the prior publications and supporting the null hypothesis for ICOGS.

For the sake of brevity, we have focused only on the salient points of Murnick's criticism. Regarding those parts of his comment that we have not discussed; differences of opinion are a natural part of the scientific endeavor and we encourage the reader to reach to their own conclusions on the basis of what has been written. We are thankful for his praise regarding some aspects of our experimental design. Perhaps his recommendations would be more helpful in other, more vital areas of scientific research.

\section{REFERENCES}

Bachor HA, Manson PJ, Sandeman RJ. 1982. Optogalvanic detection as a quantitative method in spectroscopy. Optics Communications 43(5):337-42.

Carson CG, Stute M, Ji Y, Polle R, Reboul A, Lackner KS. 2016. Invalidation of the intracavity optogalvanic method for radiocarbon detection. Radiocarbon, in press.

Galli I, Bartalini S, Cancio P, De Natale P, Mazzotti D, Giusfredi G, Fedi M, Mando P. 2013. Optical detection of radiocarbon dioxide: first results and AMS intercomparison. Radiocarbon 55(2-3): 213-23.

Genoud G, Vainio M, Phillips H, Dean J, Merimaa M. 2015. Radiocarbon dioxide detection based on cavity ring-down spectroscopy and a quantum cascade laser. Optics Letters 40(7):1342-5.

Ilkmen E. 2009. Intracavity optogalvanic spectroscopy for radiocarbon analysis with attomole sensitivity [PhD thesis]. Rutgers: Rutgers University.

Murnick D. 2015. Laser based radiocarbon analysis. International Symposium on Isotope
Hydrology: Revisiting Foundations and Exploring Frontiers. Vienna: IAEA. http://www-naweb.iaea. org/napc/ih/documents/2015_Symposium/Session4/ Murnick.pdf.

Murnick DE, Dogru O, Ilkmen E. 2008. Intracavity optogalvanic spectroscopy. An analytical technique for C-14 analysis with subattomole sensitivity. Analytical Chemistry 80(13):4820-4.

Paul D, Meijer HAJ. 2015. IntraCavity OptoGalvanic Spectroscopy is not suitable for ambient level radiocarbon detection. Analytical Chemistry 87(17): 9025-32.

Persson A, Salehpour M. 2015. Intracavity optogalvanic spectroscopy: Is there any evidence of a radiocarbon signal? Nuclear Instruments and Methods in Physics Research B 361:8-12.

Persson A, Eilers G, Ryderfors L, Mukhtar E, Possnert Gr, Salehpour M. 2013. Evaluation of intracavity optogalvanic spectroscopy for radiocarbon measurements. Analytical Chemistry 85(14): 6790-8. 